\title{
A CROSS SECTIONAL RESEARCH ON THE HEIGHT, WEIGHT AND BODY MASS INDEX OF CHILDREN AGED 5-6 YEARS IN LATVIA AND ITS SECULAR CHANGES DURING THE LAST CENTURY
}

\author{
Helena Karklina, Dzanna Krumina, Inguna Ebela, Janis Valeinis, Gundega Knipse \\ University of Latvia, Riga, Latvia
}

\section{SUMMARY}

Aim: To determine the main anthropometric parameters and their changes during the 20th and early 21 st centuries for children aged 5-6 and to analyze the nutritional level of the population based on percentage.

Methods: 536 healthy Latvian 5 and 6 year old children were randomly selected and a cross sectional survey was carried out. To collect anthropometric data, the height and weight of each child was measured and BMI calculated. The Kolmogorov-Smirnov Goodness-of-Fit test was used to assess the distribution of data; it was concluded, that the data for both boys and girls in both analyzed age groups fits a normal distribution. Using a t-test statistical tool, the results were compared to our previous study (1998/1999) and to the most significant national anthropometric investigations of the 20th century.

Results: During the last decade, the mean values of height and weight (for both boys and girls) have increased in both age groups. The mean BMI value increase for 6 year old boys and girls was not statistically significant $(p>0.05)$. The BMI mean values for 5 year old boys and girls have decreased $(p<0.05)$. In both age groups the highest percentage of children are of normal weight.

In the past 10 years the proportion of 5 year old underweight children has increased, but the proportion of overweight children has decreased percentage-wise. In all analyzed age groups a little tendency towards increase of the percentage of obese children can be observed.

From 1929 to 2007/2009, the overall mean values of height and weight have increased, but BMl mean values have decreased.

Conclusion: Positive secular changes were observed in body height and weight during the past decade $(p<0.01)$ and century. The increase in $\mathrm{BMl}$ at the beginning of the $21 \mathrm{st}$ century in comparison to the end of the 20th century may possibly be facilitated by the increased occurrence of overweight, obesity and related diseases in Latvian children. However, the number of underweight children has increased in the last decade as well.

Key words: children, BMI, height, weight

Address for correspondence: H. Karklina, Baldones Street 92, Riga, LV-1046, Latvia. E-mail: lienakarklina@inbox.lv

\section{INTRODUCTION}

Latvia is located in Northeastern Europe on the east coast of the Baltic Sea; its area is 64,589 sq.km, population (2010) 2.3 million; ethnic composition: indigenous peoples $-59.4 \%$ Latvian, 27.6\% Russian, 3.6\% Belorussian, 2.5\% Ukrainian, 2.3\% Polish, $1.3 \%$ Lithuanian, other nationalities $-3.3 \%$. According to the European Statistics of Income and Living Conditions (EU-SILC), the population health condition of Latvia is ranked low $(1,2)$. As children are the most vulnerable and sensitive part of the population and respond more quickly to changes in living conditions, their health status was assessed by evaluating their growth and development. Anthropometric changes in children in Latvia are of high public health relevance, especially due to historical circumstances of the country.

There is a risk of health disorder with the fluctuation of body mass index. During the last 30 years, adiposity in children has increased worldwide (3-5). Child and adolescent adiposity is also associated with an increased risk of emotional problems, disability and premature death in adult age (6-8). In economically developed countries, comparatively less research is done on the prevalence of underweight children and the causes and consequences thereof.

The aim of the study was to determine the changes in height, weight and BMI of children in Latvia aged 5-6 years during the 20th and the early 21 st century in order to evaluate the level of nutrition, understand the current situation, and estimate the proportion of children that are under- or overweight.

\section{MATERIALS AND METHODS}

536 healthy 5 and 6 year old children ( 253 boys and 283 girls) of all socioeconomic and ethnic groups from all regions of Latvia were randomly selected to carry out a cross sectional survey from 2007 to 2009.

The choice was determined by the correspondence of this cohort with the age of children in the older group of preschool educational institutions, which gave access to the target group and made the process of sampling and taking measurements possible. This study had some limitations - some of the parents refused to participate and there were differences in the number of children in each group. 
This might have influenced the results. Similar comments apply to the fact that no private kindergartens were included.

Inquiry forms and study protocols were approved on November 26, 2007 by the Latvian Research Ethics Commission of the Latvian Institute of Experimental and Clinical Medicine. Prior to the start of this study, a permission from the Department of Education and Science of Riga Council as well as a permission of the respective regional Education Department was received. Procedure of research was coordinated with the respective selected kindergarten's directors.

The children were divided into groups by age and gender. Preschool children aged 4.49 to 5.5 years were considered to belong to the 5 year olds group, similarly 6 year old children group included those whose age at the definite screening time ranged from 5.51 to 6.5 years. Because of the large number of ethnically mixed marriages, the ethnic background of children was not taken into consideration. As per the WHO guidelines, the anthropometric data was obtained by measuring height, weight, and chest, waist, and hip circumferences for all children. Measurements were done in accordance with the WHO methodical recommendations issued in 2007 and Latvian growth charts $(9,10)$. Measuring was done by means of electronic medical scales with $\pm 0.01 \mathrm{~kg}$ accuracy and a vertical metal stadiometer (ruler) with a sliding rod (measurement accuracy $\pm 0.1 \mathrm{~cm}$; made by Wiha Division KWB Switzerland). These tools were also used for taking measurements in 1998. All children were anthropometrically measured by a trained researcher from the Medical Faculty of University of Latvia. The obtained results were summarized numerically and graphically. For the purpose of this article, only body weight, height and BMI values were used.

In order to evaluate the secular changes in the growth process in the last 90 years, the results were then compared with the results of the most significant anthropometrical investigations of Latvian children in the 20th century:

1) data about 374 boys and 326 girls from our previous research conducted in 1998/1999 measured by Martin-Saller's method (1957) (10);

2) data about 201 boys and 202 girls from a cross sectional research conducted in 1977 by R. Millere and K. Segleniece (11);

3) data about 200 boys and 200 girls from a cross sectional research conducted in 1962/63 by K. Segleniece (12);

4) data about 229 boys and 206 girls measured and published in 1929 by K. Ādamsons (13).

We analyzed BMI, which WHO recommends as the most adequate index for evaluating nutritional status (9).

Only a few previous investigations could be used for comparison due to limited research in the past. Studies that did not include children from the entire territory of Latvia were excluded. Some studies have used Rohrer's index to define nutritional value; these values were converted into the more commonly used BMI:

$$
B M I=\frac{W}{H^{2}}
$$

where $W$ denotes body weight $(\mathrm{kg})$ and $H$ denotes height (m).

The following formula was used to determine whether body weight or height has had a greater effect on BMI in the time periods researched:

$$
\frac{W_{2}}{H_{2}^{2}}-\frac{W_{1}}{H_{1}^{2}}=\left(\frac{W_{2}}{H_{2}^{2}}-\frac{W_{1}}{H_{1}^{2}}\right)+\left(\frac{W_{2}}{H_{1}^{2}}-\frac{W_{1}}{H_{1}^{2}}\right)
$$

where $W_{2}, H_{2}$ and $W_{1}, H_{1}$ denote weight and height in the present and previous time periods, respectively. The shorter notation for this is:

$I_{T}=I_{H}+I_{W}$, where $I_{T}$ is the total change of BMI, $I_{H}$ and $I_{W}-$ the influence of height and weight on BMI (14).

According to the growth charts of Latvian children, the study subjects were divided into four groups, using the percentile scale and summing up the critically low and decreased body mass percentage: the values of BMI up to 15th percentile (underweight), from 15.1 to 85 th percentile (normal weight), from 85.1 to 97 th percentile (overweight) and more then 97 th percentile (obesity).

The SPSS version 19.0 program for Windows was used for statistical analysis. The measurements, stratified by age groups, were computed as a mean (M) and standard deviation (SD), standard error (SEM) and in percentiles. Gender differences were assessed by using an independent t-test. The p-values were obtained from the two-sample t-test for the difference of means of height, weight and BMI in 1997/1998 and 2007/2009. The $\alpha$ level was set at 0.05 and CI $95 \%$.

\section{RESULTS}

The mean values of height, weight, and BMI as well as the influence of height and weight on BMI in 1998 and 2007 are shown in Table 1. The most recently obtained data of 2007/2009 was compared with data from the previous period (1998/1999).

During the last decade, it was noted that the mean values of height (for both boys and girls) differed significantly in both age groups $(p<0.01)$. The mean values of weight were statistically different in 5 and 6 year old boys and girls $(p<0.01)$. The mean BMI value increase in 6 year old boys and girls was not statistically significant $(\mathrm{p}>0.05)$. The BMI mean values in 5 year old boys and girls decreased during recent decades $(p<0.05)$.

Gender dimorphism of mean values of anthropometric parameters was observed: boys height, weight and BMI values are higher than those of girls in both age groups, but statistically significant differences were observed in 5 year olds $(\mathrm{p}<0.05)$.

In the last decade, BMI decrease in 5 year old boys is due to height increase (height influence $I_{H}$ is negative, thus $H_{2}>H_{1}$ ) which dominates over the weight increase ( $I_{W}$ is positive, thus $W_{2}$ $\left.>W_{l}\right)$. In 6 year old boys BMI change is not significant, still it is positive. In this case the influence of height increase is about the same as influence of weight increase. However, in this case the weight increase slightly dominates over the height increase. In 5 and 6 year old girls the influence of height and weight on BMI is similar to that of 5 and 6 year old boys.

Figure 1 shows the number and percentage of children classified as underweight, normal, overweight, and obese according to BMI, using percentile scales developed for the child population of Latvia from 2007/2009 and 1998/1999 samples (10).

The data indicates that in both age groups the highest percentage of children is of normal weight. In the last 10 years, the percentage of underweight children has increased in three age groups: 5 year old boys (from $10.4 \%$ to $16.4 \%$ ), 5 year old girls (from $17.1 \%$ to $20.1 \%$ ), and 6 year old girls (from 13.4 to $17.7 \%$ ). The percentage of underweight children has decreased amongst 6 year old boys (from $18.1 \%$ to $16.2 \%$ ).

Analysis of the nutritional status of 5 year old children shows that during the last decade the percentage of overweight children 


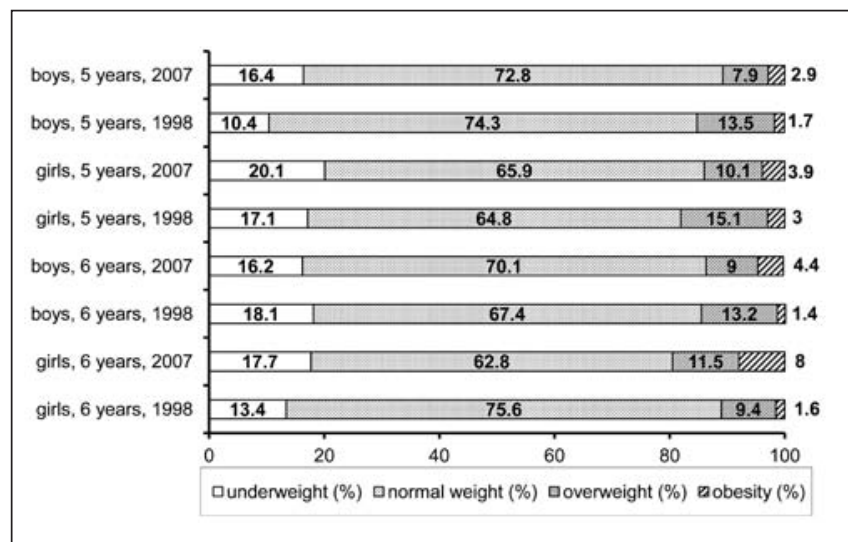

Fig. 1. Nutritional level by BMI percentile values and its percentage distribution in 5 and 6 year old children.

has decreased for 5 year old boys (from 13.5 to 7.9) and 5 year old girls (15.1 to 10.1) as well as for 6 year old boys (from 13.2 to 9.0 ), but has increased for 6 year old girls (from 9.4 to 11.5).

In all analyzed age groups a tendency towards an increase of percentage of obese children was observed.

Tendencies of secular changes in BMI, using the available data, are shown in Table 2. Changes in BMI in 5 and 6 year old children from 1929 to 2007/2009 are not relevant, as they do not even reach $0.5 \mathrm{~kg} / \mathrm{m}^{2}$.

Analyzing these changes by time periods, it can be noted that the BMI mean values from 1929 to 1962/1963 increased in girls in both age groups. In this period, BMI mean values increased slightly in 5 year old boys but decreased slightly in 6 year old boys.

From 1962/63 to 1977, BMI values decreased in boys and girls.

From 1977 to $1998 / 1999$, BMI values remained constant with small changes and this corresponded well with the weight and height dynamics.
According to data from the last research (2007/2009), the largest difference in BMI was observed in research from 1977 in 6 year old boys $(-0.23)$ (Table 2$)$.

\section{DISCUSSION}

In the last 30 years, spread of adiposity in adults and children has been observed in the world. During our research we evaluated the nutritional status of 5 and 6 year old children and analyzed its changes in the last decade in order to understand whether there is a similar situation in Latvia.

During the last century, Latvia has suffered during two world wars, a socialist revolution and the loss of independence, which was followed by genocide, deportation, and occupation. Latvia regained independence after 50 years of socialist regime. The ethnic situation in Latvia underwent major changes after Latvia lost its independence in 1940 and even more so after the Second World War. These changes include a large number of ethnically mixed marriages, the majority between Russians and Latvians.

Upon regaining independence (1991), health care and social care systems collapsed. Eating habits changed because of rise of unemployment and impoverishment of people. According to data collected by UNICEF, the number of children living in poverty reached its highest level in Latvia in the nineties (15). The old USSR system was destroyed, but a new social safety net had not been created and it influenced child development parameters including body height and weight. Research done and Reports to UN written by Latvian Save the Children show that since 1993, most families with children have been living below real existence minimum $(16,17)$. Anthropometric data from 1998/1999 (Growth charts) is based on children who were born and raised during these years.

Table 1. Anthropometric characteristics and the influence of height and weight on BMI values for 5 and 6 year old children

\begin{tabular}{|c|c|c|c|c|c|c|c|c|c|}
\hline Gender & Age (years) & $\mathrm{N}$ & Year & $\begin{array}{c}\mathrm{BMI}^{*}\left(\mathrm{~kg} / \mathrm{m}^{2}\right) \\
(\mathrm{SD})\end{array}$ & $\begin{array}{l}\text { Height } \\
\text { (cm) H } \\
\text { (SD) }\end{array}$ & $\begin{array}{c}\text { Weight (kg) } \\
\text { W } \\
\text { (SD) }\end{array}$ & $\begin{array}{c}\text { BMI change } \\
\text { in compari- } \\
\text { son to } 1998 \\
\left(I_{T}\right)\end{array}$ & $\begin{array}{c}\text { Height } \\
\text { influence } \\
\left(I_{H}\right)\end{array}$ & $\begin{array}{c}\text { Weight } \\
\text { influence } \\
\left(I_{w}\right)\end{array}$ \\
\hline \multirow{4}{*}{ Boys } & \multirow{2}{*}{5} & 139 & 2007 & $\begin{array}{c}15.7^{* *} \\
(1.5)\end{array}$ & $\begin{array}{c}116.3^{* * *} \\
(5.2)\end{array}$ & $\begin{array}{c}21.4^{* * *} \\
(3.2)\end{array}$ & \multirow{2}{*}{-0.32} & \multirow{2}{*}{-1.65} & \multirow{2}{*}{1.34} \\
\hline & & 230 & 1998 & $\begin{array}{l}16.0 \\
(1.2)\end{array}$ & $\begin{array}{l}111.0 \\
(4.7) \\
\end{array}$ & $\begin{array}{l}19.6 \\
(2.4) \\
\end{array}$ & & & \\
\hline & \multirow{2}{*}{6} & 114 & 2007 & $\begin{array}{l}15.9 \\
(1.8)\end{array}$ & $\begin{array}{c}121.0^{* * *} \\
(3.6)\end{array}$ & $\begin{array}{c}23.3^{\star * *} \\
(1.8)\end{array}$ & \multirow{2}{*}{0.03} & \multirow{2}{*}{-1.06} & \multirow{2}{*}{1.10} \\
\hline & & 144 & 1998 & $\begin{array}{l}15.9 \\
(1.4)\end{array}$ & $\begin{array}{l}117.5 \\
(4.7)\end{array}$ & $\begin{array}{l}21.8 \\
(2.8)\end{array}$ & & & \\
\hline \multirow{4}{*}{ Girls } & \multirow{2}{*}{5} & 179 & 2007 & $\begin{array}{c}15.4^{* *} \\
(1.6)\end{array}$ & $\begin{array}{c}115.3^{* * *} \\
(5.5)\end{array}$ & $\begin{array}{c}20.5^{* * *} \\
(3.2)\end{array}$ & \multirow{2}{*}{-0.33} & \multirow{2}{*}{-1.83} & \multirow{2}{*}{1.50} \\
\hline & & 199 & 1998 & $\begin{array}{l}15.8 \\
(1.3)\end{array}$ & $\begin{array}{l}110.0 \\
(4.7)\end{array}$ & $\begin{array}{l}18.7 \\
(2.5)\end{array}$ & & & \\
\hline & \multirow{2}{*}{6} & 104 & 2007 & $\begin{array}{l}15.8 \\
(2.0)\end{array}$ & $\begin{array}{c}121.2^{* * *} \\
(5.8)\end{array}$ & $\begin{array}{c}23.2^{* * *} \\
(4.1)\end{array}$ & \multirow{2}{*}{0.17} & \multirow{2}{*}{-1.14} & \multirow{2}{*}{1.31} \\
\hline & & 127 & 1998 & $\begin{array}{l}15.6 \\
(1.3)\end{array}$ & $\begin{array}{l}116.0 \\
(5.0)\end{array}$ & $\begin{array}{l}21.4 \\
(2.8)\end{array}$ & & & \\
\hline
\end{tabular}

${ }^{*} \mathrm{BMI}$ calculated from the mean values of weight and height.

${ }^{* *}$ statistical differences between sample at the level $p \leq 0.05$; ${ }^{* *}$ statistical differences between sample at the level $p \leq 0.001$ 
Table 2. Relation between 20th century anthropometric parameters and 2007/2009 research

\begin{tabular}{|c|c|c|c|c|c|c|c|c|}
\hline Age (years) & $\mathrm{N}$ & BMI $\left(\mathrm{kg} / \mathrm{m}^{2}\right)$ & Height (cm) & Weight (kg) & $\mathrm{N}$ & BMI $\left(\mathrm{kg} / \mathrm{m}^{2}\right)$ & Height $(\mathrm{cm})$ & Weight (kg) \\
\hline & \multicolumn{4}{|c|}{ Boys } & \multicolumn{4}{|c|}{ Girls } \\
\hline \multicolumn{9}{|c|}{1929} \\
\hline 5 & 110 & 0.33 & -4.3 & -1.14 & 80 & 0.09 & -5.5 & -1.8 \\
\hline 6 & 64 & 0.26 & -4.0 & -1.17 & 85 & 0.04 & -5.1 & -1.85 \\
\hline \multicolumn{9}{|c|}{ 1962/1963 } \\
\hline 5 & 100 & 0.4 & -6.34 & -1.78 & 100 & 0.5 & -5.78 & -1.4 \\
\hline 6 & 100 & 0.17 & -4.7 & -1.55 & 100 & 0.29 & -5.92 & -1.81 \\
\hline \multicolumn{9}{|c|}{1977} \\
\hline 5 & 100 & 0.01 & -5.1 & -1.82 & 101 & 0.21 & -3.4 & -0.92 \\
\hline 6 & 101 & -0.23 & -2.81 & -1.27 & 101 & 0.04 & -2.46 & -0.97 \\
\hline \multicolumn{9}{|c|}{ 1998/1999 } \\
\hline 5 & 230 & 0.31 & -5.3 & -1.84 & 199 & -0.33 & -5.3 & -1.48 \\
\hline 6 & 144 & -0.04 & -4.5 & -1.47 & 127 & 0.17 & -5.2 & -1.81 \\
\hline
\end{tabular}

Around the year 2000, living conditions in Latvia improved, mostly due to the financial politics of banks where almost anyone could apply for a loan to improve living conditions. In comparison to data from 1998, when an extensive study was carried out in Latvia, the data acquired in 2007/2009 shows that 5 and 6 year old children became taller and heavier. The analysis of anthropometric parameters in 2007 samples showed that there was an average height increase of $4.4 \mathrm{~cm}$ in boys and $5.3 \mathrm{~cm}$ in girls in the analyzed age groups during the past decade (Table 1). Mean BMI values have significantly increased in the 6 year old group but decreased in the 5 year old group. Table 2 shows that both factors - height and weight - have had the following effect on BMI changes: the increase of body height in 5 year old boys occurred faster than increase in body weight, which resulted in a decrease of BMI, and, similarly, the increase of body weight in 5 year old girls was slower than the increase in height, which resulted in a statistically significant decrease in BMI. It is difficult to determine what caused the statistically significant change in BMI in the 5 year old group in 2007/2009. The situation is characterized by several indirect indicators; for example, in 2006, $77 \%$ of households in Latvia could not afford to cover mandatory health payments (18). Also, the at-risk-of-poverty rate for a family consisting of two parents and three children was $52 \%$ in 2006, but for one parent with one child - 34\% in 2007 (19).

This hypothesis is supported by the fact that in Latvia, in comparison to other countries, many other indicators of child health and well-being declined fast, such as infant and child $>5$ years of age mortality, the prevalence of vaccine-dependent diseases, such as tuberculosis, and the spread of other infectious diseases.

In Latvia, paediatricians have reported that they observe serious cases of adiposity more often in recent years. Numerous physicians and health care professionals believe that the situation in the Baltic states is similar to that of wealthy Western countries with developed democracies, aggressive marketing of fast food, and society tending towards a hypodynamic lifestyle. Unfortunately, the child population is not an exception to this observation (20).

In order to investigate the structure of nutritional status in the population in more detail, we created four groups according to percentile values: underweight, normal weight, overweight, and obesity and compared them to similar groups of 1998 (Fig. 1).

By researching the epidemiology of adiposity and increased body weight, we have come to the conclusion that the prevalence of low body weight is similar to the prevalence of overweight and obesity in Latvia.

Assessing the percentage distribution of nutritional level, we can see that the highest percentage of children is of normal weight, almost at the same level as in 1998/1999. There is a small tendency towards obesity in all age groups. In 19.5\% of cases, 6 year old girls have extra body mass, which is why additional research should be done on the lifestyle of this age group. In the other age groups, the percentage of overweight children has decreased in the period from $1998 / 1999$ to $2007 / 2009$.

BMI values under the 15 th percentile have to be considered as underweight and the children with these values need special attention and additional health check-ups. It is disturbing that the percentage of underweight children has increased during the last decade - in 5 year old boys and in 6 year old girls from 10.4 to 16.4 and 13.4 to 17.7 , respectively.

Underweight can occur due to medical or social reasons. In order to help such children, we have to evaluate whether the reason for being underweight might be a disease, for example: food allergy, celiac disease, or helminths. Quite commonly the reason is not insufficient but rather unwholesome nutrition, but these factors have not been analyzed in this article.

Looking at the history of the dynamics of BMI in the last 90 years, links can be made to the overall situation in the country. Body height is the most sensitive anthropometric parameter related to changes in socioeconomic conditions of the population concerned (21).

As only the mean values of body height and weight were known for the first three samples $(1929,1962 / 1963,1977)$, no data base of these studies was available and different measuring tools were used, therefore, it was possible to determine only the tendency of changes but not to provide an exact analysis of anthropometric parameters and to evaluate the factors which affected them.

In 1929, children had small height and weight values because of the difficult conditions during the postwar period (13). After the 
country's economy prospered, the height of the surveyed children greatly increased in all age groups. In 1936, L. Krastiņa-Jēruma noted that Latvian children were among the tallest in Europe (22). The mean values of height from 1962/1963 to 1977 (socialism period) increased slightly, but weight practically remained the same. Measurements of 1977 reflect the anthropometrical parameters of children that had grown up in Soviet times. Since the end of World War II, living conditions have stabilized and there were no significant changes in children's height due to equal socioeconomic conditions and dietary habits in families. As both parents usually had to work full-time, most preschool children attended day nurseries and kindergartens where strict dietary standards were maintained.

In 1998/1999 (after regaining independence), body height decreased again because, as mentioned before, these children were born and grew up right after Latvia regained independence for the second time and was facing the collapse of economy. In 2007/2009, body height and weight mean values were the highest.

In 1998, Latvian growth charts were prepared to match the ethnic situation based on longitudinal and cross sectional research. Primary data was collected randomly between 1998 and 1999 from almost all regions of Latvia (10). It is important to continue research to accurately determine and update the Latvian growth charts as the circumstances are changing rapidly, especially considering economical crisis.

Therefore, the influence of historical factors should be taken into account when comparing the development of these anthropometric parameters in Latvia to other countries, which have been in a similar political and economical situation since 1990. On the other hand, this points out a new direction for research - the need to investigate the development of anthropometric parameters in groups of children in relation to the influence of macroeconomic factors within the Baltic region.

\section{CONCLUSIONS}

Significant positive changes have been observed in body height and weight during the past decade. There is no sign of an adiposity epidemic in pre-school children, although at the beginning of the 21 st century, a small tendency towards obesity was observed. A significant proportion of preschool age children have been found to be underweight in Latvia, which should be considered a dangerous risk factor for their health and quality of life. In the past 90 years, the height of children has increased more than weight in both age groups and there has been an overall decrease in BMI.

\section{Conflict of Interest}

None declared

\section{REFERENCES}

1. Gigele I, Rozentale G, Skrule J, Stale M. Justice and solidarity in the field of health. Riga: SVA; 2008. (In Latvian.)

2. The data source in the European Statistics of Income and Living Conditions (EU-SILC) survey of 2009. Luxembourg: Publications Office of the European Union; 2010.

3. European charter on counteracting obesity. In: Proceedings of the WHO European Ministerial Conference on Counteracting Obesity; 2006 Nov
15-17; Istanbul, Turkey. Copenhagen: WHO Regional Office for Europe; 2007.

4. Branca F, Nicogosian H, Lobstein T, editors. The challenge of obesity in the WHO European Region and the strategies for response: summary. Copenhagen: WHO Regional Office for Europe; 2007.

5. Prevalence of overweight and obesity in children and adolescents. Fact sheet 2.3 [Internet]. Geneva: WHO Global InfoBase; 2009 [cited 2013 Feb 25]. Available from: http://www.euro.who.int/_data/assets/ pdf_file/0005/96980/2.3.-Prevalence-of-overweight-and-obesity-EDITED_layouted_V3.pdf

6. Boney CM, Verma A, Tucker R, Vohr BR. Metabolic syndrome in childhood: association with birth weight, maternal obesity, and gestational diabetes mellitus. Pediatrics. 2005 Mar;115(3):e290-6.

7. Britz B, Siegfried W, Ziegler A, Lamertz C, Herpertz-Dahlmann BM, Remschmidt H, et al. Rates of psychiatric disorders in a clinical study group of adolescents with extreme obesity and in obese adolescents ascertained via a population based study. Int J Obes Relat Metab Disord. 2000 Dec;24(12):1707-14.

8. Reinehr T. Complications of obesity in childhood and adolescence [Internet]. Berlin: Arbeitsgemeinschaft Adipositas im Kindes- und Jugendalter (AGA); 2002 [cited 2013 Feb 25]. Available from: http://www.a-g-a.de/ Folgeenkrankungen.doc. (In German.)

9. De Onis M, Garza C, Onyango AW, Martorell R, editors. WHO child growth standards. Acta Paediatr. 2006 Apr;95 Suppl 450:5-101.

10. Krumina D, Kokare I, Bikis E. Estimation of Latvian schoolchildren's physical development. Riga: Medical Publishers; 2007. (In Latvian.)

11. Millere R, Segleniece K. Child's growth and development. Riga: Publishing house Zvaigzne; 1977. (In Latvian.)

12. Segleniece KB. Social microsphere and physical development of children. Riga: Zinatne; 1978. (In Russian.)

13. Adamsons K. Average body height and weight of the schoolchildren. Nākotnes Spēks. 1929;131-5. (In Latvian.)

14. Savickaja GV. Analysis of economic activity of an enterprise. Pt 2. Minsk: Publishing house Ekoperspektiv; 1999. (In Russian.)

15. UNICEF Innocenti Research Centre. Innocenti Social Monitor 2004: economic growth and child poverty in the $\mathrm{CEE} / \mathrm{CIS}$ and the Baltic states. Florence: UNICEF; 2004.

16. Alternative report to the United Nations on the situation in area of protection on the rights of the children in Latvia 1998-2000 [Internet]. Riga: Latvian Save the Children; 2002 [cited 2013 Feb 25]. Available from: www.crin.org.

17. Children's report to the United Nations on implementation of the UN convention on the rights of the child in Latvia [Internet]. Riga: Latvian Save the Children; 2006 [cited 2013 Feb 25]. Available from: www.crin. org.

18. Out of pocket health payments in households of Latvia and their impact on the capacity to pay: analytical report. WHO: Riga; 2008.

19. Children in Latvia. European Statistics of Income and Living Conditions (EU-SILC) survey. Riga: Central Statistical Bureau of Latvia; 2009.

20. Rubana IM, Velika B, Grinberga D, Pudule I, Tilgale N, Trapencieris M. Investigation of children's anthropometric parameters and school environment in Latvia. Riga: SVA; 2008. (In Latvian.)

21. Wolanski N. Genetic and ecological factors in human growth. Hum Biol. 1970 Sep;42(3):349-68.

22. Krastina-Jeruma L. Anthropological data on Latvian school youth. Proceedings of University of Latvia. Medical Faculty Series. 1937;3(12):235-72. (In Latvian.) 